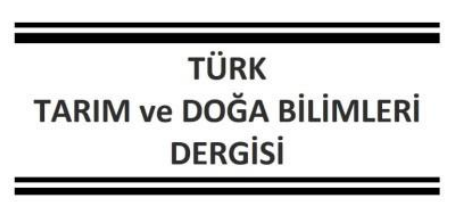

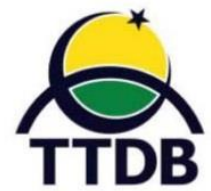

www.dergipark.gov.tr/turkjans

Araştırma Makalesi

\title{
Quince A Anacının Çöğür Anacı Olarak Kullanım Potansiyelinin Belirlenmesi
}

\author{
Müge ŞAHIN ${ }^{1 *}$ \\ ${ }^{1}$ Ege Tarımsal Araştırma Enstitüsü, Meyvecilik Şubesi, i̇zmir/Türkiye \\ *Sorumlu Yazar:mugesahin67@hotmail.com
}

Geliş Tarihi: 18.12.2021 Düzeltme Geliş Tarihi: 10.06.2021 Kabul Tarihi: 01.07.2021

\section{Öz}

Yumuşak çekirdekli meyve türleri içerisinde üretimi en yüksek olan üçüncü tür ayvadır ve artan üretim ile birlikte bu tür için uygun anaçlara olan ihtiyaçta artış göstermektedir. Son zamanlarda anaç üretiminde vejetatif yöntemlerin yaygın olarak kullanılmasının yanı sıra bu yöntemdeki bazı dezavantajlardan dolayı generatif yöntemlerinde kullanımı bir hayli yükselmiştir. Bu çalışmada, dünyada yaygın olarak ayva, armut ve yenidünya meyve türleri için anaç olarak kullanılan Quince $A$ anacının çöğür anacı olarak kullanım potansiyeli araştııımıştır. Tohumlara $+4 \mathrm{CO}$ de 8 hafta soğuk katlama uygulaması yapılmış ve maksimum çimlenme oranına (\% 73.5), tohum ekiminden 25 gün sonra ulaşılmıştır. Çöğür gelişimi ile ilgili gövde çapı, sürgün boyu ve pişkinlik oranı parametreleri ve bunların minimum, maksimum, ortalama, standart sapma ve varyasyon katsayıları belirlenmiştir. Çöğürlerde gövde çapı 4.91-7.98 mm, sürgün boyu 20.02-46.60 cm, pişkinlik oranı ise 2.86-8.34 $\mathrm{cm} / \mathrm{mm}$ arasında değişim göstermiştir. Bununla beraber çöğürlerin gövde çapı, sürgün boyu ve pişkinlik oranı varyasyon katsayıları sırasıyla $\% 11.99, \% 23.48$ ve $\% 22.80$ olarak tespit edilmiştir. Sonuçlarımıza dayanarak hem çimlenme hem de homojen çöğür gelişimi açısından Quince A'nın çöğür anacı olma potansiyelinin yüksek olduğu söylenebilir.

Anahtar kelimeler: Cydonia oblonga M., çöğür anacı, pişkinlik oranı, çimlenme oranı, varyasyon katsayısı

\section{Assessment of the potential use of Quince A as a seedling rootstock}

\begin{abstract}
Quince is the 3rd species with the highest production among pome fruits and need for suitable rootstocks increases with increasing production. Wide use of vegetative methods in rootstock production has some disadvantages so generative methods are used recently. In this study, the using potential of Quince A rootstock, which is widely used in the world as rootstock for both quince, pear and loquat, was investigated. Cold stratification were applied at +4 CO for 8 weeks to seeds and the maximum germination rate $(73.5 \%)$ was reached 25 days after sowing. Stem diameter, shoot length and sturdiness quotient parameters with their minimum, maximum, average, standard deviation and variation coefficients were determined. The stem diameter, shoot length and sturdiness quotient varied between 4.91-7.98 mm, 20.02-46.60 cm, and 2.86-8.34 $\mathrm{cm} / \mathrm{mm}$, respectively. Coefficients of variation were found $11.99 \%$ for stem diameter, $23.48 \%$ for shoot length, and $22.80 \%$ for sturdiness quotient rate. In conclusion, it has been observed that quince $A$ has a high potential for seedling rootstock in terms of germination and homogenous seedling development.
\end{abstract}

Key words: Cydonia oblonga M., seedling rootstock, sturdiness quotient, germination rate, variation coefficient

Giriş

Ayva (Cydonia oblonga Mill.), yumuşak çekirdekli meyve türleri içerisinde elma ve armuttan sonra üretimi en yüksek olan türdür ve ülkemiz dünya ayva üretiminin $\% 25^{\prime}$ ini karşılamaktadır (FAOSTAT, 2017). Bu türün çeşit olarak kullanımının yanı sıra, anaçlarının armut ve yenidünya yetiştiriciliğinde de kullanılması, yüksek verim, erken olgunlaşma, bodur gelişim, tohum ve doku kültürü yöntemleri ile kolaylıkla çoğaltılması özellikleri ile de ön plana çıkmaktadır (Lombard ve 
Westwood, 1987; Dolcet-Sanjuan ve ark., 1990; Morini ve Sciutti, 1991; Marangoni ve Mazzanti, 1999; Sansavini, 2007; Tepe ve Koyuncu, 2019). Son 20 yılda sadece dünya ayva üretimindeki artışın \% 90 civarında olduğu (FAOSTAT, 2017) ve bu oranın gün geçtikçe hasat, depolama ve pazarlama kolaylıkları göz önünde bulundurularak artan bir eğilim sergilediği göz önünde bulundurulduğunda (Şahin ve Mısırlı, 2016), ayva anaçlarına olan ihtiyacın önemi anlaşılmaktadır.

Meyve türlerinin çoğaltımı, vejetatif ve generatif yöntemler olmak üzere iki şekilde gerçekleştirilmektedir. Son zamanlarda meyve anaçlarının üretiminde vejetatif üretim tekniklerinden biri olan ve kısa sürede kitlesel bitki üretiminin sağlandığı doku kültürü yöntemi yaygın olarak kullanılsa da, bu yöntemde türlere özgü yaşanılan sorunlar, maliyeti yüksek alt yapı, aletekipman ve konu uzmanı personel ihtiyacı gibi dezavantajlar bulunmaktadır. Öte yandan ayvada yapılan çelikle veya daldırma ile çoğaltma gibi diğer vejetatif üretim yöntemlerinde ise köklenme sorunları yaşanabilmekte ve hatta bazı anaçlarda köklenme hiç meydana gelmemektedir (Browning ve Watkins, 1991; Aygun ve ark., 2006; Atay ve ark., 2011). Önceki çalışmalar incelendiğinde, Quince A anacının odun çelikleriyle köklenebildiği ve arazi koşullarına \% 49 oranında bir uyum gösterdiği, yanısıra Quince C'nin \% 67 oranında ve yeni ıslah edilen anaç adaylarının ise \% 37-64 arasında uyumlu olabildiği rapor edilmiştir (Browning ve Watkins, 1991). Ülkemizde yapılan çalışmalar incelendiğinde, yaygın yetiştiricilik alanı olan Ege 2, Ege 22 ve Eşme çeşitlerinin odun çeliklerinin köklenme oranları sırasıyla \% 64.0, \% 40.0 ve \% 24.5 olarak tespit edilmiştir (Atay ve ark., 2011). Bununla beraber S.Ö ayva anaçlarının ise hendek daldırma yöntemiyle köklenme oranının \% 0-79.52 arasında değişim gösterdiği bildirilmiştir (Aygun ve ark., 2006).

Vejetatif üretimi zor ve maliyeti yüksek olan meyve türleri için generatif (tohum) çoğaltım yönteminin küçük işletmeler ve çiftçiler tarafından tercih edildiği bildirilmektedir (Yıldırım ve Koyuncu, 2005; Şahin ve ark., 2020a). Meyve türlerine göre değişmekle birlikte ülkemizde ve dünyada halen çöğür anacı kullanımı önemli oranlarda gerçekleştirilmektedir ve çöğür anacı kullanımı bazı kalite özellikleri bakımından ön plana çıkmaktadır (Gülcan, 1991; Çelik ve ark., 2000; Koyuncu ve ark., 2000; Yıldırım ve Koyuncu, 2005; Rubio-Cabetas, 2012; Szymajda ve ark., 2019; Tepe ve Koyuncu, 2019; Kaçal ve ark., 2020). Nitekim Isparta ilinde yapılan bir çalışmada, kayısı, vişne ve armut fidanlarının tamamının çöğür anaçları ile çoğaltıldığı ve elma ile ayva türünde çöğür anacı kullanım oranının sırasıyla \%24 ve \%52 olarak gerçekleştiği tespit edilmiştir (Yıldırım ve Koyuncu, 2005). Öte yandan yenidünya yetiştiriciliğinde ayva çöğür anaçlarının kullanılmasının, meyve ağırlığı ve meyve kalitesinde artışa neden olduğu belirlenmiştir (Polat, 1995; Demir ve Durceylan, 1998; Tepe ve Koyuncu, 2019). Genel olarak çöğür anaçlarında aranan en önemli özelliğin yüksek çimlenme oranı ve homojen çöğür gelişimi olduğu bilinmektedir.

Doğu Marmara Bölgesi'nde, ateş yanıklığına tolerant ayva tiplerinin belirlenmesine yönelik yapılan survey çalışmasında belirlenen "Acı ayva" olarak adlandırılan yerel ayva tipinin tohumdan geliştiği (Şahin ve ark., 2020a) ve söz konusu bu tipin tohumlarının o yörede bulunan fidan üreticileri tarafından anaç üretiminde kullandıkları bilinmektedir. Fidan üreticileri tarafından, bölge koşullarına adapte olmuş ve bölgede doğal yayılım alanı olan bu ayva tipinin homojen çöğür gelişim sağladığı, ayva çeşitleri ile aşı uyuşma sorununun olmadığı ve bazı hastalıklara toleranslı olduğu gözlemlenmiştir. Önceki çalışma sonuçları dikkate alındığında, sert çekirdekli, yumuşak çekirdekli ve sert kabuklu meyve türlerinde çöğür anaçlarının anaçlık performanslarına yönelik araştırmaların yapıldığı (Koçal ve Pırlak 2011; Yılmaz ve Akça, 2016; Kaya ve ark., 2018) ancak ayva türünün anaçlık özellikleri ile ilgili çalışmaların sınırlı sayıda olduğu söylenebilir (Bolat, 1994). Bu nedenlerden dolayı hem ülkemiz hem de dünyada yumuşak çekirdekli meyve türleri arasında önemli bir yere sahip olan ayva türünde çöğür anaçlarının kullanımına yönelik yeni çalışmaların yapıımasına intiyaç vardır. Bu bağlamda mevcut çalışma ile; dünyada ve ülkemizde yaygın olarak kullanılan ve ayva yetiştiriciliğinin en önemli sorunlardan biri olay ateş yanıklığına orta düzeyde duyarlı (\% 37.16 SLB) olarak bilinen (Şahin ve ark., 2020b) ve dünyada yaygın bir kullanım alanı bulunan Quince A ayva anacının çöğür anacı olarak kullanım potansiyeli araştırılmıştır.

\section{Materyal ve Metot}

\section{Bitki materyali, tohumların temini, soğukta katlama ve tohum ekimi}

Çalışmada bitki materyali olarak, Ege Tarımsal Araştırma Enstitüsü Müdürlüğüne ait, Ayva Genetik Kaynakları parselinde yer alan Quince A anacına ait tohumlar kullanılmıştır. Meyveler hasat edildikten sonra tohumlar gölgede kurutulmuş ve soğukta katlamaya alınana kadar oda sıcaklığında bekletilmiştir. Ardından Ocak ayı ortasında, tohumlar nemli perlit içerisinde + 4 CO de 8 hafta boyunca soğukta katlama işlemine tabi tutulmuştur. Tohumlar içerisinde torf + ağaç 
kabuğu bulunan 2 l'lik saksılara 30 Mart 2016 tarihinde ekilmiştir.

\section{Çöğürlerde çimlenme gücü ve çimlenme hızının belirlenmesi}

Tohumların çimlenme gücü ve çimlenme hızının belirlenmesi amacıyla toplamda 200 tohum ekilmiş ve denemeler tesadüf parselleri deneme desenine göre 4 tekerrürlü ve her tekerrürde 50 tohum olacak şekilde organize edilmiştir. Hartman ve Kester (1975)'e göre, tohumların çimlenme gücü (\%) ve çimlenme hızı (gün) belirlenmiştir.

\section{Çöğürin gelişim gücünün belirlenmesi}

Çimlenme ile ilgili parametreler incelendikten sonra, çöğürlerde 2 yıl boyunca gübreleme, sulama, ot alma, budama vb. kültürel işlemler homojen ve düzenli olarak gerçekleştirilmiştir. Çöğürler içerisinden 120 çöğür tesadüfi olarak seçilerek, çöğür gelişim parametrelerinin incelenmesi amacıyla kurulan 2. denemeye alanına aktarılmıştır. İkinci deneme parseli tesadüf parselleri deneme desenine göre 5 tekerrürlü ve her tekerrürde 24 çöğür olacak şekilde tasarlanmıştır. Çöğür gelişimi ile ilgili olarak çöğür çapı, sürgün boyu ve pişkinlik oranı parametreleri, iki yaşlı çöğürlerde incelenmiştir. Çöğür çapları toprak seviyesinden $15 \mathrm{~cm}$ yukarıda olacak şekilde dijital kumpasla (mm) Ekim ayında, çöğür boyu $(\mathrm{cm})$ ise bir yaşlı taze sürgünün bitki büyüme noktasına kadar olan mesafe olacak şekilde şerit metre ile Temmuz ayında ölçülmüştür. Pişkinlik oranı, sürgün uzunluğunun $(\mathrm{cm})$ bitki çapına $(\mathrm{mm})$ oranı şeklinde belirlenmiştir (Thompson, 1985).

\section{Verilerin analizi}

Çalışma kapsamında değerlendirilen çimlenme gücü ve çimlenme hızı değerleri \% olarak belirlenmiştir. Incelenen diğer parametrelerin istatistiksel analizinde JMP 7.0 paket programı kullanılmıştır. Çöğür gelişim parametrelerindeki homojenite tespiti için, çöğür boyu, gövde çap ölçümleri ve pişkinlik oranları dikkate alınarak varyasyon katsayısı (VK) hesaplanmıştır. Bireylere ait tanımlayıcı istatistiksel parametreler (minimum, maksimum, ortalama ve standart sapma) incelenmiştir.

\section{Bulgular ve Tartışma}

Bulgularımızda tohum ekiminden 13 gün sonra Quince A anacının tohumlarının \%37.5 oranında çimlenme gösterdiği ve tohum ekiminin 13-16 günleri arasında ise \% 50 çimlenme gücüne ulaştığı tespit edilmiştir. Tohum ekiminden 25 gün sonra çöğürler maksimum çimlenme oranına ulaşılmış (\% 73.5) ve bu sürenin sonunda çimlenme son bulmuştur (Çizelge 1). Bulgularımız Sugar, Champion, Cheldow, Manning, Mato Dentro, Mendoza Inta-37, Portugal ve Smyrna ayva çeşitlerinin tohum çimlenme ve çöğür potansiyellerinin incelendiği önceki çalışmalar ile uyum içerisindedir. Zira yapılan çalışmalarda, Sugar, Champion, Cheldow, Manning, Mato Dentro, Mendoza Inta-37, Portugal ve Smyrna ayva çeşitlerinin çimlenme yüzdelerinin \% 73.68-86.41 arasında değişim gösterdiği tespit edilmiştir. Öte yandan Portugal (\% 86.41), Cheldow (\% 84.38), Mato Dentro (\% 82.00) ve Champion (\% 81.54) çeşitlerinde ise çimlenme yüzdelerinin mevcut bulgularımızdan daha yüksek olduğunu tespit edilmiştir (Dall'Orto ve ark., 2007).

Çizelge 1. Quince A tohumlarının çimlenme gücü (\%) ve çimlenme hızı (gün) değerleri

\begin{tabular}{lcrrrrr}
\hline & & \multicolumn{5}{c}{ Tohum ekiminden sonraki çimlenme hızı } \\
\cline { 3 - 7 } & Çimlenme özellikleri & 13 gün & 16 gün & 19 gün & 22 gün & 25 gün \\
\hline \multirow{2}{*}{ Quince A } & Çimlenen tohum (adet) & 75 & 130 & 141 & 141 & 147 \\
& Çimlenme gücü (\%) & 37.5 & 65 & 70.5 & 70.5 & 73.5 \\
\hline
\end{tabular}

Yumuşak çekirdekli meyve türlerinde yapılan çalışmalar incelendiğinde, bir çok meyve türünün optimum çimlenme oranına ulaşması için soğukta katlamanın yapılması gerektiği ve bunun yanı sıra sıcaklık, hormon ve kimyasallar gibi ön uygulamaya ihtiyaç duyduğu görülmüştür (El-Dengawy, 2005; Niu ve ark., 2012; Pipinis ve ark., 2012; Hai-qing ve Hai, 2014; Yan, 2017; Kaçal ve ark., 2020). Bunlara ilave olarak Malus, Pyrus, ve Cydonia genuslarında sadece soğukta katlama uygulamasının çimlenme sorununu ortadan kaldırdığı bildirilmiştir (Yilmaz, 2008; Şahin ve ark., 2020c). İlaveten, Japon ayvasında ise sadece $+4 \mathrm{oC}^{\prime}$ de 1 aylık soğukta katlama uygulaması sonucunda, çimlenme ekimden 18 gün sonra başlamış ve 31 . gün sonunda \% 96.42 çimlenme oranıyla son bulmuştur (Şahin, 2020). Her ne kadar litaratürlerde ayva türünde tohum çimlenmesi için soğukta katlama süreleri 
üzerine çalışmalar sınırlı olsa da mevcut sonuçlarımız farklı türler üzerine yapılan soğuklama süresi ve çimlenme oranları ile uyum içerisindedir.

Çöğür anaçlarında aranan başlıca özelliklerden biri tohumlarının ön işleme gerek duymadan en düşük maliyetle çimlenme oranının yüksek olmasıdır (Kaya ve ark., 2018). Bu çalışmadan elde edilen bulgular ile soğukta katlama uygulamasına ek bir ön uygulama yapılmadan Quince A tohumlarının çimlenme oranlarının yüksek olduğu belirlenmiştir. Bu tarz anaçlarda aranan diğer önemli özellikler ise homojen çöğür gelişimidir. Çalışmamızda 120 çöğürde gövde çapı, bir yıllık sürgün boyu ve pişkinlik oranına ait tanımlayıcı istatistikler Tablo 2'de görülmektedir. Yapılan istatistiksel değerlendirmelerde her üç parametreye ait verilerin normal dağılış gösterdiği belirlenmiştir (Şekil 1). Sırasıyla, gövde çapı 4.91$7.98 \mathrm{~mm}$, sürgün boyu $20.02-46.60 \mathrm{~cm}$, pişkinlik oranı ise $2.86-8.34 \mathrm{~cm} / \mathrm{mm}$ arasında değişim göstermiştir (Çizelge 2).

Çizelge 2. Quince A çöğürlerine için sürgün boyu $(\mathrm{cm})$, gövde çapı $(\mathrm{cm})$ ve pişkinlik oranı $(\mathrm{cm} / \mathrm{mm})$ değerlerine ait tanımlayıcı istatistiksel verileri

\begin{tabular}{lccccc}
\hline Parametreler & Minimum & Maksimum & Ortalama & Standart hata & VK (\%) \\
\hline Sürgün boyu $(\mathrm{cm})$ & 20.02 & 46.60 & 34.20 & 1.27 & 23.48 \\
Gövde çapı $(\mathrm{mm})$ & 4.91 & 7.98 & 6.28 & 0.12 & 11.99 \\
Pişkinlik oranı $(\mathrm{cm} / \mathrm{mm})$ & 2.86 & 8.34 & 5.47 & 0.20 & 22.80 \\
\hline
\end{tabular}

Farklı bitki türlerinde yapılan çalışmalar, ölçülen parametreler bakımından varyasyon katsayısının \% 20'den az olması durumunda incelenen bireyler arasında homojen bir dağılımın olduğu varsayılmaktadır (Liu ve ark., 2020). Varyasyon katsayısının düşük olması ortalama verilerden olan standart sapmanın düşük olduğunu ve güvenilirliğinin yüksek olduğunu göstermektedir. Ayrıca tohum anacı ıslahına yönelik yapılan tartılı derecelendirme skalasında, varyasyon katsayısı değerinin düşük olduğu anaç adaylarının daha yüksek puan aldığı bildirilmiştir (Kaya ve ark., 2018). Bulgularımızda çöğürlerin gövde çapı verilerinin istatistiksel analizi sonucundan elde edilen \% 11.99'luk varyasyon katsayısı bakımından varyasyonun düşük olduğu ve çöğürlerin homojen yapıda olduğunu söylenebilir. Ayrıca çöğürlerde sürgün boyu ve pişkinlik oranı bakımından sırasıyla \% 23.48 ile \% 22.80'lik varyasyon katsayısı değerlerinin (Çizelge 2) popülasyona ait değerlerin normal dağılış gösterdiğini (Şekil 1) ve elde edilen sonuçlarda varyasyonun kabul edilebilir düzeyde olduğunu ifade edilebilir.
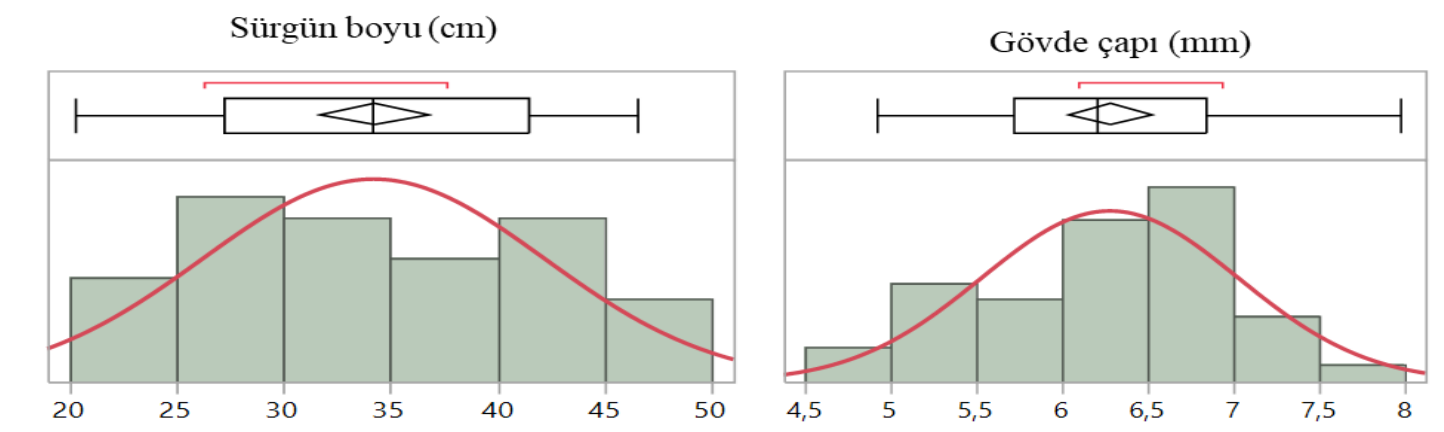

Pişkinlik oranı $(\mathrm{cm} / \mathrm{mm})$

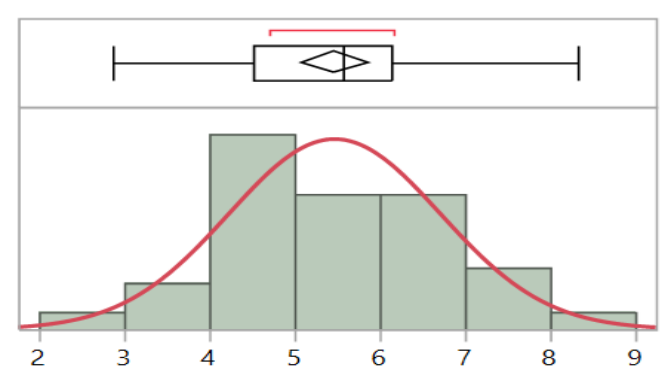

Şekil 1. Quince A çöğürlerine ait sürgün boyu $(\mathrm{cm})$, gövde çapı $(\mathrm{cm})$ ve pişkinlik oranı $(\mathrm{cm} / \mathrm{mm})$ değerlerinin dağılımı. 
Yabani kayısı çöğür anaç adaylarının (zerdali) tohum anacı olarak kullanım potansiyellerinin araştırıldığı bir çalışmada, iki yıl ve iki farklı lokasyonda yapılan değerlendirmeler sonucunda sürgün çapı ve sürgün uzunluğundaki varyasyon katsayısı sırasıyla \% 5.11-25.33 ve \% 4.47-33.30 arasında değişim göstermiştir (Kaya ve ark., 2018). Bolat (1994), elma, ayva, zerdali, şeftali, erik ve mahlepte çöğür gelişimini, sürgün çapı ve sürgün uzunluğu parametrelerindeki varyasyonu inceleyerek belirlemiş ve elma çöğürlerinde her iki parametredeki varyasyon diğer türlere oranla daha yüksek olarak tespit etmiştir. Sekiz ayva çeşidinin çöğür performanslarının incelendiği çalışmada, çöğür çapının 5.8-6. 7 mm arasında olduğu tespit edilmiştir (Dall'Orto ve ark., 2007). Çalışmamıza benzer şekilde ayva çögürlerinde, sürgün çapındaki VK \% 15.38, sürgün uzunluğundaki VK ise \% 15.70 olarak hesaplanmış ve çöğür anacı olarak kullanımının uygun olduğu düşünülmüştür (Bolat, 1994). Bu bakımdan mevcut çalışmadan elde edilen bulgularımız önceki çalışmalar ile benzerlik göstermektedir.

Öte yandan çöğürlerde pişkinlik oranı, çöğürlerin gelişim parametrelerinin değerlendirilmesinde ön plana çıkan diğer bir parametredir (Thompson, 1985) ve iki çöğür aynı sürgün boyuna sahip iken gövde çapı daha yüksek olanın daha pişkin olduğu şeklinde yorumlanmaktadır (Yılmaz ve Akça, 2016). Yüksek pişkinlik oranı, fidan kalitesi için olumlu bir belirleyici olarak oldukça kabul görmesine rağmen (Tsakaldimi ve ark., 2013), pişkinlik oranı ve fidan kalitesi arasındaki ilişki net olarak çözülememiştir (Bayala ve ark., 2009). Pişkinlik oranının çok yüksek değerlerde olması ise istenmeyen bir özelliktir ve çöğürlerin pişkin kabul edilebilmesi için pişkinlik oranının $6(\mathrm{~cm} / \mathrm{mm})^{\prime}$ dan az olması gerektiği bildirilmektedir (Jaenicke, 1999) ve bu çöğürlerin dengeli bir sürgün gelişimi gösterdiği anlamına gelmektedir (Yılmaz ve Akça, 2016). Çalışmamızdan elde edilen $2.86-8.37(\mathrm{~cm} / \mathrm{mm})$ arasında değişen ve ortalaması $5.47(\mathrm{~cm} / \mathrm{mm})$ olan pişkinlik oranı, çöğürlerin önemli bir kısmının pişkin olduğunu göstermektedir.

\section{Sonuç ve Öneriler}

Çalışma bulgularına dayanarak hem tohum çimlenme özellikleri bakımından hem de homojen çöğür gelişimi açısından Quince A'nın çöğür anacı olma potansiyelinin yüksek olduğu söylenebilir. Quince $A$ anacının ayva dışında armut, yenidünya gibi farklı meyve türlerinde anaç olarak kullanılması da göz önüne alındığında, mevcut bulgularımızın özellikle doğadan farklı yerel ayva tiplerinin tohumlarını toplayarak çögür anacı olarak kullanan küçük ve orta ölçekli fidan üreticileri ve bu konularda çalışan araştırıcılara faydalı olacağı düşünülmektedir.

\section{Kaynaklar}

Atay, E., Gargın, S. Çalhan, Ö., Atay, N. A., Butar, S. 2011. Ege-2, Ege-22 ve Eşme Ayva Çeşitlerinin Odun Çelikleriyle Çoğaltılması. Uluslararası Katılımlı I. Ali Numan Kıraç Tarım Kongresi ve Fuarı, 2441-2444.

Aygun, A., San, B., Dumanoglu, H. and Celik, M. 2006. Propagation by mound layering of some selected "SO" quince genotypes (Cydonia oblonga) as compatible rootstocks for pears (Pyrus communis). New Zealand Journal of Crop and Horticultural Science, 34; 191-193.

Bayala, J., M. Dianda, J. Wilson, S.J. Ouédraogo and K. Sanon, 2009. Predicting field performance of five irrigated tree species using seedling quality assessment in Burkina Faso, West Africa. New For., 38: 309-322.

Bolat, í. 1994. Erzincan Bahçe Kültürleri Araştırma Enstitüsü fidanlık arazisinde bazı meyve türlerinde çöğür gelişiminin incelenmesi üzerine bir araştırma. Atatürk Ü. Zir. Fak. Der, 25(1): 67-77.

Browning, G. \& Watkins, R. 1991. Preliminary evaluation of new quince (Cydonia oblonga Miller) hybrid rootstocks for pears, Journal of Horticultural Science, 66:1, 35-42, DOI: 10.1080/00221589.1991.11516122

Browning, G., \& Watkins, R. 1991. Preliminary evaluation of new quince (Cydonia oblonga Miller) hybrid rootstocks for pears. Journal of Horticultural Science, 66(1), 35-42.

Çelik, H., M. Çelik, R. Yalçın, 2000. Türkiye'de Meyve ve Asma Fidancılığının Stratejik Açıdan Değerlendirilmesi. II. Ulusal Fidancılık Sempozyumu. 25-29 Eylül 2000 Ödemiş-Bademli

Dall'Orto, F. A. C., Ojima, M., Pio, R., \& Chagas, E. A. 2007. Avaliação da capacidade reprodutiva de algumas cultivares de marmeleiros visando a obtenção de portaenxertos. Ciência e Agrotecnologia, 31(2): 274-278.

Demir, Ş., Durceylan, M.E. 1998. Yenidünya Anaç Projesi. T.C. Tarım ve Köyişleri Bakanlığı Tarımsal Araştırmalar Genel Müdürlüğü Narenciye ve Seracılık Araştırma Enstitüsü, Sonuç Raporu, $16 \mathrm{~s}$.

Dolcet-Sanjuan, R., Mok, D.W.S., Mok, M.C., 1990. Micropropagation of Pyrus and Cydonia and their responses to Fe-limiting conditions, Plant Cell Tiss. Organ Cult., 21, 191-199. 
El-Dengawy, E. R. F. 2005. Promotion of seed germination and subsequent seedling growth of loquat (Eriobotrya japonica, Lindl) by moist-chilling and $\mathrm{GA}_{3}$ applications. Scientia Horticulturae, 105(3), 331-342.

FAOSTAT, 2017. Food and Agriculture Organization of the United Nations. Available at: http://www.fao.org/faostat/en/\#data.

Gülcan, R., 1991. Meyve Ağaçlarında Anaç Islahı. Türkiye 1. Fidancılık Sempozyumu. Ankara, 185-194.

Hai-qing, Y. U., \& Hai, H. U. 2014. Investigation on Seed Characteristics and Germination Conditions of Malus toringoide. Journal of Sichuan Forestry Science and Technology, 2014, 35(3): 61-64. doi: 10.16779/j.cnki.1003-5508.2014.03.014

Jaenicke, H. 1999. Good tree nursery practices: practical guidelines for research nurseries. ICRAF, Nairobi, pp 8-15.

Kaçal, E., Çalışkan, O., Arif, Atak., Aydınlı, M., Öztürk, G., ve Bayav, A. 2020. Karadut tohumlarının çimlenmesi üzerine prolin ve sıcaklık uygulamalarının etkileri. Mustafa Kemal Üniversitesi Tarım Bilimleri Dergisi, 25(2), 181-188.

Kaya, Ö., Şahiner Öylek, H., Keskin, S., Aslan, A., Esmek, i., Özkan, N., Kokargül, R., Albayrak, S., Ercişli, S., Kan, T. 2018. Selection of seedling rootstock for apricot. Research in Plant Bology. 8: 29-36. doi: 10.25081/ripb.2018.v8.3659

Koçal, H., Pırlak, L. 2011. Bazı Prunus Klon ve Çöğür Anaçlarının Alyanak ve Roksana Kayısı Çeşitleriyle Aşı Uyuşma Düzeylerinin Belirlenmesi. Ege Üniversitesi Ziraat Fakültesi Dergisi, 48(1), 39-45.

Koyuncu, F., M.A. Aşkın, K. Kepenek, 2000. Isparta Yöresinde Meyve Fidanı Üretim Durumu. II. Ulusal Fidancılık Sempozyumu. 25-29 Eylül 2000 Ödemiş-Bademli

Liu, B., Zhao, D., Zhang, P., Liu, F., Jia, M., \& Liang, J. 2020. Seedling evaluation of six walnut rootstock species originated in China based on principal component analysis and cluster analysis. Scientia Horticulturae, 265, 109212.

Lombard, P. B. and Westwood, M. N., 1987. Pear rootstocks, in Rootstocks for Fruit Crops, eds. R. C. Rom and R. F. Carlson (New York, NY: John Wiley and Sons, Inc.), 145-183.

Marangoni, B., Mazzanti, F. 1999. Pear rootstocks. Informatore Agrario Supplemento, 55(6): 33-38.

Morini, S. and Sciutti, R., 1991. In vitro propagation of quince clonal rootstoks, Agric. Mediterr., $121,56-59$.
Niu, X., Zhang, L., Liu, L., \& Zhao, Y. 2012. Effect of different treatment on seed germination of Malus baccata. Guizhou Agricultural Sciences, (11):56-62.

Pipinis, E., Milios, E., Karaoglanidou, E., \& Smiris, P. 2012. Effects of gibberellic acid, kinetin and cold stratification on seed germination of Pyrus pyraster Burgsd. and Malus dasyphylla Borkh. species. In International Scientific Conference Forests in FutureSustainable Use, Risks and Challenges. Institute of Forestry, Belgrade (Serbia).

Polat, A.A. 1995. Quince-A anacının yenidünyalarda vegatatif büyüme üzerine etkileri. Derim, 12(2):84-88.

Rubio-Cabetas, M.J., 2012. Present and future trends in peach rootstock breeding worldwide. Acta Hortic. 962, 81-90. https://doi.org/10.17660/ActaHortic.2012.9 62.10.

Sansavini, S., 2007. Portinnesti, In: Angelini, R. (Ed.), II pero. Bayer Crop Science S.r.l., Milan, Italy, pp. 270-281.

Szymajda, M., Sitarek, M., Pruski, K., \& Żurawicz, E. 2019. A potential of new peach (Prunus persica L.) seed tree genotypes for the production of generative rootstocks. Scientia Horticulturae, 256, 108618.

Şahin, M., 2020. Seedling Properties and Fire Blight Resistance on open pollinated Chaenomeles japonica Hybrids in Turkey. II. International Agricultural, Biological \& Life Science Conference September 1-3, 2020. Edirne, Turkey. Proceeding book p. 1152-1160.

Şahin, M., Mısırlı, A., Gökkür, S., Aksoy, D., \& Özaktan, H. 2020c. Application of Hybridization Breeding Technique for Fire Blight Resistance on Cydonia Oblonga: A Base Study on Susceptibility, Heterosis, and Heterobeltiosis Parameters, International Journal of Fruit Science, 20:sup3, S1458S1469, DOI: 10.1080/15538362.2020.1804515

Şahin, M., Mısırlı, A., Özaktan, H. 2020 b. Determination of fire blight (Erwinia amylovora) susceptibility in Turkey's Cydonia oblonga Mill. Germplasm. European Journal of Plant Pathology. 157(2):227-237. doi: 10.1007/s10658-02001971-5.

Şahin, M., Mısırlı, A., Özaktan, H. 2020a. Ateş Yanıklığına Tolerant Ayva Tiplerinin Seleksiyon Islahı: Doğu Marmara Bölgesi. Anadolu Ege Tarımsal Araştırma Enstitüsü Dergisi 30(1):1-10. doi: 10.18615/anadolu.727173. 
Tepe, S., Koyuncu, M. A. 2019. Farklı anaçların 'Akko XIII' yenidünya çeşidinde meyve kalitesi üzerine etkileri. Derim 36(2):135-140 doi: 10.16882/derim.2019.567965

Thompson, B. E. 1985. Seedling morphological evaluation- What can you tell by looking? In: "Evaluating seedling quality: principles procedures and predictive abilities of majortests" (Duryea ML ed). Proc. Workshop 16-18 October 1984. For. Res Lab., Oregon State University, Corvallis, Oregon, pp. 59-71.

Tsakaldimi, M., P. Ganatsas and D.F. Jacobs, 2013. Prediction of planted seedling survival of five Mediterranean species based on initial seedling morphology. New For., 44: 327339.

Yan, W. 2017. Effects of different treatments on the germination of Malus hupehensis
(Pamp) Rehd Seeds. Agricultural Technology \& Equipment, (6), 2.

Yıldırım, A. N., Koyuncu, F. 2005. Isparta Iili Meyve Fidancılığı Üzerine Bir Çalışma. Derim, 22(1), 20-28.

Yılmaz, S., \& Akça, Y. 2016. Tüplerde yetiştirilen farklı ceviz (Juglans regia) çeşitlerine ait çöğürlerin bazı morfolojik özelliklerinin ve kalitelerinin belirlenmesi. Gaziosmanpaşa Üniversitesi Ziraat Fakültesi Dergisi. 33 (3): 157-166. doi:10.13002/jafag950.

Yilmaz, M. 2008. Optimum germination temperature, dormancy, and viability of stored, non-dormant seeds of Malus trilobata (Poir.) C.K. Schneid. Seed Science and Technology 36: 747-756. 